\title{
Constituição e atravessamentos de uma escola referência em educação bilíngue para surdos
}

Constitution and crossings of a reference school in bilingual education for deaf

Constitución y cruces de una escuela de referencia en educación bilingüe para sordos

\author{
Neoli Paulina da Silva Gabe \\ Mestra pela Universidade Federal de Santa Maria, Santa Maria, Rio Grande do Sul, Brasil. \\ neoligabe@hotmail.com \\ ORCID - https://orcid.org/0000-0003-1764-1827
}

Carmen Vieira Mathias

Professora doutora na Universidade Federal de Santa Maria, Santa Maria, Rio Grande do Sul, Brasil. carmen@ufsm.br

ORCID - https://orcid.org/0000-0001-5667-159X

Recebido em 6 fevereiro 2019

Aprovado em 16 de abril de 2020

Publicado em 26 de outubro de 2020

\section{RESUMO}

Este artigo de cunho bibliográfico tem como objetivo caracterizar o ambiente que deu origem à pesquisa, isto é, uma escola de surdos e ouvintes. Nessa instituição, o ensino fundamental é dividido em duas modalidades, a saber, as turmas regulares de ouvintes e as turmas em classes especiais. Nesse segundo caso, as aulas são bilíngues, ou seja, ministradas, exclusivamente, para alunos surdos, em Língua Brasileira de Sinais (LIBRAS), por professores fluentes nessa língua. Nas classes bilíngues, a $1^{a}$ língua é a Libras, na modalidade gestual/visual, e a $2^{a}$ língua é o português escrito. Neste artigo, são elencados os atravessamentos que a instituição passou para manter as classes bilíngues no ensino fundamental, isto é, o mínimo que a comunidade surda almeja para garantir seus direitos. O artigo também constitui uma síntese da história da educação de surdos e do processo de formação dos profissionais que atuam nessa instituição referência em educação de surdos. Palavras-chave: Instituição de ensino; educação de surdos; educação bilíngue.

\section{ABSTRACT}

This bibliographic article aims to characterize the environment that gave rise to the research, that is, a school for the deaf and hearing. In this institution, elementary education is divided into two modalities, namely, regular classes of listeners and classes in special classes. In this second case, the classes are bilingual, that is, taught exclusively to deaf students, in Brazilian Sign Language (LIBRAS), by teachers fluent in that language. In bilingual classes, the 1st language is Libras, in sign / visual mode, and the 2nd language is written Portuguese. This article lists the crossings that the institution went through to maintain bilingual classes in elementary school, that is, the minimum that the deaf community aims to guarantee their rights. The article also constitutes a synthesis of the 
http://dx.doi.org/10.5902/1984686X42414

history of education for the deaf and the process of training professionals who work in this institution that is a reference in the education of the deaf.

Keywords: Educational institution; deaf education; bilingual education.

\section{RESUMEN}

Este artículo bibliográfico tiene como objetivo caracterizar el entorno que dio lugar a la investigación, es decir, una escuela para sordos y oyentes. En esta institución, la educación primaria se divide en dos modalidades, a saber, clases regulares de oyentes y clases en clases especiales. En este segundo caso, las clases son bilingües, es decir, impartidas exclusivamente a estudiantes sordos, en lengua de señas brasileña (LIBRAS), por maestros que dominan ese idioma. En las clases bilingües, el primer idioma es Libras, en modo de señas / visual, y el segundo idioma se escribe portugués. Este artículo enumera los cruces por los que pasó la institución para mantener clases bilingües en la escuela primaria, es decir, lo mínimo que la comunidad sorda tiene como objetivo garantizar sus derechos. El artículo también constituye una síntesis de la historia de la educación para sordos y el proceso de formación de profesionales que trabajan en esta institución que es una referencia en la educación de sordos.

Palabras clave: Institución de enseñanza; educación para sordos; educación bilingüe.

\section{Introdução}

A história da educação de surdos, na maioria das bibliografias, possui uma cronologia bastante linear, ou seja, vai desde um período de isolamento ou exclusão até uma fase de celebração da diferença.

A educação de surdos, normalmente, é relatada pela perspectiva ouvinte e, eventualmente, contada por surdos. Os surdos são os protagonistas dessa história, mas, em geral, são relacionados como apenas coadjuvantes. Nos relatos, é possível verificar as deduções dos ouvintes em relação à vida do sujeito surdo. Mas, mesmo que a história tenha ocorrido através do percurso dos ouvintes, é importante dar uma base sobre os primórdios da educação de surdos no Brasil, um marco histórico para a comunidade surda.

Tal como as instituições europeias, as primeiras instituições brasileiras também se destinavam aos deficientes auditivos e visuais, por acreditar-se que os mesmos necessitavam de adaptações de procedimentos pedagógicos mais simples em relação às demais deficiências. No decorrer desse percurso histórico, iniciou-se um processo contra o formalismo humanista, e a educação passou a ser científica, passando a constituir outras narrativas em relação à educação dos ditos anormais, através da crença de que a criança, ao nascer, é uma tábua rasa passível de ser educada. Ao considerar todos os sujeitos educáveis, produziram discursos e condições que possibilitaram a emergência do campo designado educação especial. (LUNARDILAZZARIN, 2003, apud GUEDES, 2012, p. 21). 
Em 1857, foi fundada a primeira escola para surdos no Rio de Janeiro, o "Imperial Instituto dos Surdos-Mudos", hoje, Instituto Nacional de Educação de Surdos (INES). Hoje, o INES um órgão do Ministério da Educação que, segundo informações da página na web da própria instituição, oferta as seguintes modalidades de ensino à comunidade surda:

O Ensino Básico oferecido no Colégio de Aplicação (CAp/INES), contempla a Educação Precoce (de recém-nascidos a três anos), Educação Infantil, Ensino Fundamental e Ensino Médio, atendendo aproximadamente 500 alunos. Os professores que atuam na Educação Básica dedicam-se também à realização de estudos e pesquisas sobre sua prática, à elaboração de materiais de apoio à educação de surdos e na capacitação de recursos humanos, deslocando-se pelo país e até para o exterior para prestar assessoria técnica aos sistemas de ensino, disseminando conhecimentos e práticas na área da surdez. [...] O Instituto Nacional de Educação de Surdos, único em âmbito federal, ocupa importante centralidade na educação de surdos, tanto na formação e qualificação de profissionais na área da surdez, por meio da Educação Superior - Ensino de Graduação e Pós-Graduação, Pesquisa e Extensão - quanto na construção e difusão do conhecimento, por meio de estudos e pesquisas, fóruns de debates, publicações, seminários e congressos, cursos de extensão e assessorias em todo o Brasil. (BRASIL, 2012).

A criação do INES remonta toda a trajetória da educação de surdos no Brasil, pois é através dele que a comunidade surda e grupos de surdos começaram a sentir-se pertencentes a um grupo social.

Por conseguinte aos movimentos para a manutenção dos direitos da comunidade surda, o presente artigo aborda a constituição histórica da educação de surdos em uma escola pública. A referida escola é referência para a comunidade surda regional, localizada no interior do Rio Grande do Sul, e serviu de base para uma pesquisa realizada em nível de mestrado. Observa-se que a trajetória da Escola Rosário (ER), local em que transcorre a pesquisa, não foi encontrada em nenhum documento oficial. Assim, optou-se por pesquisar como ocorreu a chegada dos alunos surdos na referida instituição, iniciando por esclarecer um pouco sobre as noções da identidade surda, da Libras e da construção cultural existente dos sujeitos surdos.

Pensando na constituição do sujeito surdo, essencial ao exercício da vida e à educação desses indivíduos, será abordada a história da instituição de ensino que deu origem ao presente estudo.

Além disso, será discutido como ocorreu o processo de transição dos alunos surdos para a ER. Essa mudança foi motivada pela facilidade de acesso a transportes públicos e por ser uma instituição que possibilitaria aos alunos concluir o Ensino Médio, fortalecendo os laços entre os sujeitos da comunidade surda na escola. 
http://dx.doi.org/10.5902/1984686X42414

\title{
Contextualizando a história da educação de surdos no brasil
}

Mesmo com conquistas obtidas pela comunidade surda, como, por exemplo, usar a Língua de Sinais como primeira língua, no século XIX, o Brasil ainda não havia constituído uma política educacional que legitimasse a educação para surdos.

Em 1911, o INES, seguindo uma tendência mundial, regimentou, em seu currículo, o Oralismo $^{1}$ como modalidade de ensino. Mesmo proibido o uso da língua de sinais, em movimento de resistência, os surdos continuaram a utilizá-la pelos corredores da escola. Em 1957, a diretora da instituição proibiu oficialmente o uso de sinais e instituiu que os alunos que usassem a língua de sinais seriam punidos. Ainda assim, fora do instituto, os surdos continuavam a "falar" através de sinais, principalmente nas comunidades que se formavam nos grandes centros urbanos do país.

Entretanto, a história da educação de surdos no Brasil vai além da fundação do Instituto, no Rio de Janeiro. Muitas outras iniciativas e movimentos foram desenvolvidos em outros estados brasileiros. Baleiro (1989, p. 60 apud Carvalho, 2010, p. 26) salienta que:

\begin{abstract}
na cidade de São Paulo, foi a iniciativa particular e religiosa que marcou o início do atendimento educacional do surdo (1933), tornando-se único por duas décadas. É somente a partir de 1950 que surgiram as primeiras iniciativas da rede municipal de ensino e de pais de surdos as primeiras delas foram o Instituto Hellen Keller ${ }^{2}$ e o Instituto Educacional de São Paulo. A rede estadual de ensino manifestou-se apenas em 1957, criando classe especial para atendimento dos alunos surdos, em escala regular. Tanto o Instituto Hellen Keller quanto o Instituto Educacional de São Paulo utilizavam-se do método oral. (CARVALHO, 2010, p. 26).
\end{abstract}

Fronza e Muck (2012) relatam que, na década de 70, chegou, ao Brasil, o método da Comunicação Total, através de uma professora ${ }^{3}$ da Universidade de Gallaudet. De acordo com essa proposta, o aluno surdo poderia escolher se queria oralizar, sinalizar ou fazer leitura labial, conforme melhor lhe conviesse. Porém, isso não se efetivou na prática, visto que cada instituição conduzia as práticas educativas conforme sua preferência.

A Comunicação Total inclui todo o espectro dos modos linguísticos: gestos criados pelas crianças, língua de sinais, fala, leitura orofacial, alfabeto manual, leitura e escrita. A Comunicação Total incorpora o desenvolvimento de quaisquer restos de audição para a melhoria das habilidades de fala ou de leitura orofacial, através de uso constante, por um longo período de tempo, de aparelhos auditivos individuais e/ou sistemas de alta fidelidade para amplificação em grupo. (FREEMAN, CARBIN, BOESE, 1999, p. 171).

Somente na década de 80 é que inicia, no Brasil, as discussões sobre o Bilinguismo, tendo em Brito (1986) os primeiros argumentos em defesa dessa proposta educacional. Dentre as propostas educacionais sugeridas para a educação de surdos, o bilinguismo é 
http://dx.doi.org/10.5902/1984686X42414

foco das discussões entre os profissionais da área, uma vez que visa atender às necessidades do aluno surdo e respeitar suas diferenças linguísticas.

Alguns estudiosos da educação de surdos, como Góes (1996), Quadros (1997, 2005), Fernandes e Rios (1998), Salles et al. (2002), Correia e Fernandes (2005), entre outros, consideram o bilinguismo a modalidade de ensino que mais aproxima-se dos anseios da comunidade surda. Além disso, a literatura indica que tal proposta é utilizada, com frequência, pelas escolas que propõem aos sujeitos surdos duas línguas no contexto escolar.

Fronza e Muck (2012) defendem que a proposta de educação bilingue é a mais adequada para o ensino de crianças surdas, tendo em vista que considera a língua de sinais como primeira língua e, a partir disso, passa para o ensino da segunda língua, que pode ser na modalidade escrita ou oral. Importante esclarecer o conceito de Libras, segundo Quadros (2006),

\begin{abstract}
A língua de sinais é uma língua espacial-visual e existem muitas formas criativas de explorá-la. Configurações de mão, movimentos, expressões faciais gramaticais, localizações, movimentos do corpo, espaço de sinalização, classificadores são alguns dos recursos discursivos que tal língua oferece para serem explorados durante o desenvolvimento da criança surda e que devem ser explorados para um processo de alfabetização com êxito. (QUADROS, 2006, p. 26).
\end{abstract}

Tendo em vista que a comunicação dos surdos ocorre, principalmente, mediante a língua de sinais, após uma longa trajetória de lutas da comunidade surda, a LIBRAS foi implantada como segunda língua no Brasil, conforme Lei № 10.436/2002, regulamentada por meio do Decreto 5626/2005.

Zílio (2012) faz as seguintes considerações sobre a segunda língua oficial brasileira:

A Libras é composta por sinais que correspondem, em português, a palavras, entretanto não se trata simplesmente de uma substituição, uma palavra por um sinal correspondente, ela tem suas peculiaridades, além de ser independente da língua portuguesa. Ou seja, ela não se reflete na estrutura gramatical da língua oral, mas possui uma estrutura própria, que permite que se visualize a mensagem comunicada. Para isso, cada sinal possui: uma configuração de mão (o formato que a mão, ou as mãos, tomam para realizar determinado sinal, sendo que a(s)mão(s) podem tomar outra configuração no fazer do sinal); um movimento (movimentação que a mão, ou ambas, devem fazer para sinalizar); uma locação (espaço onde a mão ou as mãos devem estar posicionadas para a sinalização); orientação (direção para a qual a mão ou as mãos se movimentarão) e expressões não manuais (expressão realizada pelo corpo ou pela face: olhos, sobrancelhas, boca, etc.). (ZILIO, 2012. p. 30). 
http://dx.doi.org/10.5902/1984686X42414

Porém, mesmo com a lei referenciada anteriormente e com o fato de que a Libras apresenta toda a estrutura de uma língua, ainda são necessárias muitas lutas da comunidade surda para que o reconhecimento social seja garantido. Por isso, a importância da constituição de uma comunidade surda, isto é, que defenda os direitos dos surdos, a exemplo da garantia de um Tradutor Intérprete de Língua de Sinais (TILS) nos diferentes espaços públicos.

O respeito à identidade surda e à cultura surda não está relacionado a estudos sobre déficit de audição, visto que esse fator não é considerado para que um sujeito seja integrante da comunidade surda. Em outras palavras, a comunidade surda é constituída tanto por indivíduos que possuem os mais variados graus de perda auditiva (por exemplo, surdos profundos, hipoacústicos levíssimos etc.) quanto por ouvintes.

Tradicionalmente, o surdo era conhecido como deficiente auditivo ou surdo-mudo. A identidade do surdo era marcada pela inexistência da fala e pela falta da audição, em uma perspectiva clínico-terapêutica. Porém, essas discussões sobre a identidade surda sofreram modificações, principalmente, a partir do reconhecimento linguístico da língua de sinais, quando se reconheceu, politicamente, a diferença surda.

\section{A constituição da história da educação de surdos na Escola Estadual de Ensino Médio Nossa Senhora do Rosário}

Em 2009, no intuito de facilitar o acesso local e educacional dos alunos surdos, iniciaram-se as tentativas de mudanças destas turmas de educandário. Os estudantes frequentavam a Escola Estadual de Ensino Fundamental Gaspar Bartholomay, na cidade de Santa Cruz do Sul, localizada no centro da cidade, e a proposta de mudança era para a Escola Estadual de Ensino Médio Nossa Senhora do Rosário (ER), no bairro Independência, bem próxima à Universidade de Santa Cruz do Sul (UNISC).

A acessibilidade dos alunos foi um dos principais fatores para que o atual educandário fosse escolhido como referência na educação de surdos na região da $6^{\text {a }}$ CRE, a qual abrange 18 municípios. Dentre os fatores de acessibilidade, estão o acesso a todos os ambientes da escola, com rampas para os cadeirantes, os espaços amplos e a proximidade com a UNISC ${ }^{4}$, o que facilita a locomoção até o transporte para os municípios vizinhos.

Outro fator considerado para a escolha dessa instituição de ensino foi que alunos surdos poderiam estudar até concluir Ensino Médio (EM), o qual era oferecido no turno da 
http://dx.doi.org/10.5902/1984686X42414

manhã e da noite. No educandário em que esses alunos estudavam anteriormente, as aulas eram ofertadas apenas para o Ensino Fundamental (EF), pois não havia EM.

A diretora da Escola Rosário relata que, na época da transição dos alunos surdos, estava "honrada e orgulhosa em receber a comunidade surda". A educadora ainda salienta que, mesmo antes dessa mudança, a escola possuía alunos cadeirantes e portadores de Síndrome de Down, ou seja, para ela a postura da escola "sempre foi de acolher o diferente".

Inicialmente, essa proposta de mudar de escola não foi aceita pela comunidade surda, em virtude de seu desconhecimento a respeito do novo ambiente de ensino e de dúvidas quanto à recepção nessa nova comunidade escolar. Observa-se que um ambiente novo pode desacomodar e trazer desafios, motivos que fez essa minoria linguística sentir-se desterritorializada.

Após tratativas e reuniões com todas as partes envolvidas, a transição foi aceita e estruturada de forma a atender, da melhor maneira possível, as necessidades da comunidade surda. Um dos anseios a serem considerados era que fosse possibilitado, aos alunos surdos, a conclusão do EM na mesma instituição, de modo que pudesse manter-se, por mais tempo, com seus pares.

Por fim, foi visto como "uma opção feita pela própria comunidade surda e sua opinião deve ser a mais importante", conforme relato da vice-diretora da Escola Gaspar Bartholomay à época. Essa mesma professora salientou, ainda, que "como é um grupo diferenciado, o contato entre eles é fundamental", bem como o acompanhamento constante desses alunos.

Passado um ano de reuniões preparatórias e encontros com grupos afins, em 2010, iniciou-se um trabalho pioneiro na ER, localizada em Santa Cruz do Sul - RS. Nesse ano, a escola passou a atender 54 alunos surdos nas chamadas classes especiais ${ }^{5}$ de surdos, oferecidas no EF. Nessas aulas, todos os alunos eram surdos e todas as aulas ministradas em Libras, por professores bilíngues. Já no EM, os alunos foram incluídos em turmas regulares, com a presença de TILS, que também eram professores da instituição de ensino, porém atuavam em outro turno ministrando aulas em Libras para as turmas em classes especiais de surdos.

Atualmente, os alunos da ER são oriundos de diferentes municípios de abrangência da região da 6 - Coordenadoria Regional de Educação (CRE). Observa-se que essa escola é considerada a mais especializada da região, haja vista que os alunos surdos são 
http://dx.doi.org/10.5902/1984686X42414

encaminhados para a instituição. Foi necessária uma parceria entre o estado e os municípios na logística de encaminhar os alunos à escola e prover o transporte para esses estudantes.

Com a chegada dessa nova modalidade de ensino, a escola, como um todo, necessitou preparar-se para o encontro entre diferentes culturas e línguas. Para isso, foi essencial a mudança no regimento da escola, que agora tem como filosofia a aceitação de diferentes culturas.

\begin{abstract}
A escola propõe uma educação transformadora, crítica, construtiva e comprometida com a conquista da cidadania, buscando também acessibilidade aos educandos surdos através da Educação Bilíngue, e, integrando-se na comunidade de forma a contribuir na construção do conhecimento voltado à conscientização e atuação coletiva, necessárias à formação de uma sociedade justa e solidária. (REGIMENTO ESCOLAR, 2017, p. 6).
\end{abstract}

Quanto ao processo de matrículas para o ingresso, com a perspectiva de universalização do ensino, visa-se atender a toda comunidade. No que diz respeito, especialmente, às situações de atendimento educacional especializado na área da surdez, a instituição estabelece que:

o ingresso de educandos surdos na escola se dá mediante comprovação da surdez através de Exame áudio-métrico, e ingressarão em Classes Especiais de Surdos no Ensino Fundamental e em Classes Regulares no Ensino Médio com apoio de Atendimento Educacional Especializado em Sala de Recursos. [...] Especificamente no caso de criança surda a matrícula será aceita a partir dos três anos de idade. Conforme dispõe as referências em Educação de Surdos o contato com outros sujeitos sinalizadores e/ou usuários da Língua de Sinais facilita a constituição da identidade e cultura surda responsável pelo desenvolvimento intelectual da criança. (REGIMENTO ESCOLAR, 2017, p. 12).

Tendo em vista esse processo de adaptação, durante o ano de 2010, o currículo escolar da instituição teve uma mudança significativa, a saber, a oferta do componente curricular Libras, com um período semanal de aula. A Libras passou a ser integrada ao componente curricular nas turmas de $5^{\underline{a}}$ a $7^{\text {a }}$ série do EF e no $1^{\circ}$ e $2^{\circ}$ ano do $E M$, com aulas ministradas por um professor surdo, isto é, sem intérprete. Constata-se, assim, que esse foi um fato histórico tanto para a comunidade da Escola Rosário quanto para o país, uma vez que se tratava de uma iniciativa inédita nesse período. Nas aulas de Libras como segunda língua - isto é, para alunos regulares ouvintes -, a metodologia empregada considerava o uso de recursos visuais como filmagens e apresentações em projetor, que são características comuns no ensino de Libras por professor surdo. 
http://dx.doi.org/10.5902/1984686X42414

No segundo ano desta experiência que considerou a Libras como componente curricular para alunos ouvintes, foi possível observar que já existiam trocas significativas entre surdos e ouvintes. Esse é a também a percepção da professora surda, a qual complementa, ainda, em suas considerações, ser evidente o interesse dos alunos ouvintes pela Libras. Dito de outra forma, é, nesse novo ambiente de aprendizagem, que eles começam a perceber a cultura surda, seu universo, sua língua. Desse modo, ocorre um processo no qual os ouvintes aprendem Libras para se comunicar e interagir com seus colegas surdos. Segundo Zandonato, Bertó e Klein (2011, p.128), "temos a certeza de que, em qualquer escola, pública ou não, onde há aluno surdo, deva a Libras ser ensinada e fazer parte do Currículo ouvinte, pois o Brasil tem hoje, duas Línguas Oficiais, a Língua Portuguesa e a Libras". Esse seria o ideal, considerando o bilinguismo das línguas oficiais vigentes no Brasil.

Em 2012, a ER começou a fazer parte do Programa Institucional de Bolsas de Iniciação à Docência (Pibid) ${ }^{6}$ UNISC, no qual, inicialmente, a proposta de atuação não incluía os alunos surdos. Após iniciadas as atividades do Pibid na escola, o programa necessitou de uma reorganização para atender à demanda da educação de surdos presente desse local.

O primeiro passo foi conseguir um professor bilíngue da escola para atuar junto ao programa, o que foi viabilizado. Em seguida, começaram os planejamentos entre os bolsistas de iniciação à docência, (alunos da graduação), supervisores (professores da escola) e coordenadores dos subprojetos da UNISC (professores da graduação) para pensar oficinas voltadas às necessidades dos alunos surdos do EF e EM.

A partir disso, foram realizadas oficinas de Matemática e Português com a participação de alunos surdos. Durante a realização das atividades, os bolsistas foram percebendo a importância do uso de recursos visuais, bem como da Língua Portuguesa escrita como segunda língua.

No ano de 2014, também foram desenvolvidas oficinas de teatro com a participação de alunos surdos e ouvintes. O Programa Institucional de Bolsas de Iniciação à Docência (PIBID) permanece com atividades na escola, contudo, sofre alterações e cortes, mantendo hoje, apenas atividades de monitoria em algumas turmas. $\mathrm{Na}$ atualidade, o Programa conta somente com o Subprojeto de Linguagens e Pedagogia.

Considerando que a formação docente é o objetivo maior do programa PIBID, as contribuições dos bolsistas que atuaram diretamente com os alunos surdos foram 
http://dx.doi.org/10.5902/1984686X42414

significativas, pois permitiram esses professores em formação vivenciassem experiências pedagógicas singulares, ou seja, que proporcionaram a desconstrução de verdades preestabelecidas e o desacomodar necessário ao profissional docente. Da mesma forma, a iniciativa proporcionou aos supervisores da escola trocas de experiências que permitiram a reflexão sobre a própria atuação docente, motivando alguns supervisores a buscarem formação no curso de tradução/interpretação de Libras.

No ano de 2014, a UNISC, universidade vizinha da escola, propôs-se a organizar o curso de extensão de tradução/interpretação de Libras. Pressupõe-se que, com a visibilidade promovida pelo evento, tenha sido percebida a importância da inserção e da disseminação da língua de sinais na comunidade.

Participaram desse curso vários professores da ER, todos eles mobilizados pela importância da língua de sinais nesse contexto educacional. Alguns docentes já eram intérpretes, mas optaram por fazer o curso para o aperfeiçoamento das estratégias de interpretação e para a ampliação do vocabulário. Outros professores realizaram o curso para poder ter fluência na Libras e para aprender técnicas de interpretação, de forma a sentirem-se mais preparados à atuação em sala de aula com alunos surdos, assim como em outros contextos em que houvesse a necessidade do TILS.

$\mathrm{Na}$ trajetória dessa instituição, é preciso elencar alguns entraves encontrados para que fosse possível manter as classes especiais, garantindo o direito dos surdos a aulas ministradas em sua primeira língua - a Libras -, na modalidade gestual/visual, e em sua segunda língua - o Português -, na modalidade escrita. Esse direito também é garantido pelo atual Plano Nacional de Educação (PNE). A Lei no 13.005, de 25 de junho de 2014, aprovou o PNE e, em sua Meta 4, que trata da educação especial e prevê 19 estratégias para universalizá-la até 2024 , preferencialmente, na rede regular, com serviços multifuncionais e serviços especializados, públicos ou conveniados, recomenda a seguinte estratégia:

4.7) garantir a oferta de educação bilíngue, em Língua Brasileira de Sinais LIBRAS como primeira língua e na modalidade escrita da Língua Portuguesa como segunda língua, aos (às) alunos (as) surdos e com deficiência auditiva de 0 (zero) a 17 (dezessete) anos, em escolas e classes bilíngues e em escolas inclusivas, nos termos do art. 22 do Decreto no 5.626, de 22 de dezembro de 2005, e dos arts. 24 e 30 da Convenção sobre os Direitos das Pessoas com Deficiência, bem como a adoção do Sistema Braille de leitura para cegos e surdos-cegos. (BRASIL, 2015). 
http://dx.doi.org/10.5902/1984686X42414

Decreto $n^{0} 5626$, de 22 de dezembro de 2005, que passa a regulamentar a Lei $\mathrm{n}^{0}$ 10.436, de 24 de abril de 2002, e o art. 18 da Lei nำ10.098, de 19 de dezembro de 2000, institui, no Capítulo IV:

Art. 14. As instituições federais de ensino devem garantir, obrigatoriamente, às pessoas surdas acesso à comunicação, à informação e à educação nos processos seletivos, nas atividades e nos conteúdos curriculares desenvolvidos em todos os níveis, etapas e modalidades de educação, desde a educação infantil até à superior. I - escolas e classes de educação bilíngue, abertas a alunos surdos e ouvintes, com professores bilíngues, na educação infantil e nos anos iniciais do ensino fundamental; II-ofertar, obrigatoriamente, desde a educação infantil, o ensino da Libras e também da Língua Portuguesa, como segunda língua para alunos surdos.

$\S 1$ ㅇ São denominadas escolas ou classes de educação bilíngue aquelas em que a Libras e a modalidade escrita da Língua Portuguesa sejam línguas de instrução utilizadas no desenvolvimento de todo 0 processo educativo. (BRASIL, 2005).

Ao assinalar a indispensabilidade de escolas ou classes bilíngues, o decreto afirma a viabilidade tanto de alunos surdos quanto de ouvintes estudarem nessas salas, mas reitera que sala bilíngue é aquela na qual a Libras é a língua de instrução, sendo as aulas também ministradas nesse idioma. Isso quer dizer que os conteúdos serão ensinados pela língua de sinais e não por meio do português, com concomitante tradução para a Libras.

Observa-se que, na referida instituição, não há nenhum caso, até o presente momento, de alunos ouvintes matriculados nas classes especiais, o que é possível, desde que o aluno ouvinte seja fluente usuário da língua de sinais.

A abrangência da escola não se limita à 6 ${ }^{\underline{a}}$ CRE. Atualmente, estudam, na instituição, duas alunas que residem em outras cidades. Mesmo que a proposta pedagógica bilíngue seja considerada um fator positivo no referido contexto, é difícil manter essa proposta enquanto instituição. Essa dificuldade é agravada a cada troca de governo e, principalmente, com as políticas de redução de gastos. No ano de 2010, já iniciou com a multisseriação nos anos inicias, em que as turmas do $1^{\circ}$ ao $5^{\circ}$ ano foram multisseriadas em apenas 3. Considera-se que essa foi uma decisão prejudicial à educação dos alunos surdos.

No final do ano de 2015, ocorreram rumores de que os alunos surdos seriam incluídos nas turmas regulares de ouvintes também no EF. Contudo, pensava-se que seria apenas uma ideia inicial do coordenador da 6 CRE, mas, no final do mês de janeiro de 2016, quando a diretora da ER realizou o gerenciamento de recursos humanos, confirmou que os alunos surdos seriam incluídos em turmas regulares de ouvintes desde os anos iniciais. 
http://dx.doi.org/10.5902/1984686X42414

$\mathrm{Na}$ última semana de janeiro, um documento expedido pela 6 a $^{\mathrm{a}} \mathrm{CRE}$ comunicou $\mathrm{o}$ fechamento das classes especiais para surdos do 6ํao 9ํano, já para o ano letivo de 2016. No início de fevereiro de 2016, a comunidade escolar, junto à comunidade surda, reuniu-se para ouvir os alunos surdos, seus familiares, lideranças surdas e os educadores de surdos de outras instituições do Rio Grande do Sul.

Após essa mobilização, sem nenhuma resposta sobre o futuro dos alunos surdos na instituição, realizou-se um abaixo-assinado e uma petição online, nos quais a comunidade requereu a não alteração das classes especiais bilíngues da referida escola. Em outras palavras, solicitou-se que essas aulas não fossem multisseriadas, bem como que possibilitassem os alunos surdos do EM a opção pelo turno de preferência com a presença de um TILS.

Além das leis citadas anteriormente, o abaixo-assinado tem sua fundamentação complementada pela Lei ำ 13.146, de 6 de julho de 2015, denominada Lei Brasileira de Inclusão da Pessoa com Deficiência (LBI), que reforça o solicitado.

\footnotetext{
Art. 28: "Incumbe ao poder público assegurar, criar, desenvolver, implementar, incentivar, acompanhar e avaliar:

IV - oferta de educação bilíngue, em Libras como primeira língua e na modalidade escrita da língua portuguesa como segunda língua, em escolas e classes bilíngues". (BRASIL, 2015).
}

Outra mobilização partiu dos pais dos alunos surdos que seriam incluídos nas classes regulares e de lideranças surdas, na qual foi realizada uma solicitação ao Ministério Público requerendo a manutenção das classes especiais de surdos no EF. Para realizar o encaminhamento de forma correta ao Ministério Público, a comunidade surda contou com o trabalho voluntário de uma equipe de advogados, que tomou conhecimento da necessidade da manutenção das classes especiais, apresentada pela comunidade surda, e advogou em favor dessa causa.

Fez parte da mobilização agendar uma reunião com o Senhor Secretário de Educação do Estado (Seduc) com o objetivo de colocá-lo a par da situação.

Na ocasião, a diretora da escola apresentou um histórico do trabalho da instituição na educação de surdos, que atende crianças e adolescentes de sete municípios. "O fechamento das classes especiais para surdos acarretaria o fim do atendimento de alunos da região vale do Rio Pardo", de acordo com a Fundação de Articulação e Desenvolvimento de Políticas Públicas para Pessoas com Deficiência e com Altas Habilidades no Rio Grande do Sul (FADERS). Essa organização também destacou que, nas classes especiais, as 
http://dx.doi.org/10.5902/1984686X42414

crianças têm aula com professores capacitados, enquanto nas regulares faz-se necessária a intermediação de um intérprete. Um argumento contra tal mudança é que ela "é um obstáculo no aprendizado, é preciso considerar as diferenças e respeitar a cultura surda" (FADERS, 2016).

O Secretário da Seduc mostrou-se solícito e entendeu melhor o contexto de educação para surdos. Ele garantiu que a situação passaria por análise para identificar os entraves à permanência dos estudantes nas classes especiais, assim como as possibilidades para a manutenção das turmas. Nas palavras do próprio Secretário de Educação à época, "Entendo que a comunidade não pode ser prejudicada por uma medida do Poder Executivo, e vamos estudar a melhor forma de solucionar a questão" (PETIÇÃO PUBLICA, 2015).

Todas essas mobilizações ocorreram no mês de fevereiro de 2016, porém, no dia 22 de fevereiro do mesmo ano, no início das aulas nas redes estaduais, os alunos surdos do EF da ER começaram o ano letivo incluídos nas turmas regulares de ouvintes com a presença de um intérprete. Segundo o coordenador da 6⿳亠丷厂 $\mathrm{CRE}$, em entrevista dada ao jornal da região, "esta medida está sendo um avanço e esclareço que está completamente baseada na legislação, que prevê a inclusão social das pessoas com deficiência...". (RIOVALE JORNAL, 2016, p. 3).

No entanto, sabe-se que o aluno surdo aprende por vias não auditivas, ou seja, por meio de uma língua gestual/visual, isto é, a Libras. Nessa língua, há um sinal próprio para objetos, verbos etc., bem como para a identificação de cada sujeito que faz parte da comunidade surda.

Ainda, em contraponto à visão do coordenador da 6 $6^{\mathrm{a}} \mathrm{CRE}$, os pais dos alunos surdos, os educadores surdos e os professores bilíngues argumentam que esses alunos precisavam aprender os conceitos básicos em todos os componentes curriculares. Essa reivindicação faz sentido, pois é nesse momento que o vocabulário avança para uma complexidade maior, ou seja, a partir do $6^{\circ}$ ano, são aprofundados os conhecimentos constituídos nos anos iniciais. Os alunos que estão no EF precisam conhecer esse novo vocabulário e dar significado a ele. O surdo não estaria aprendendo na sua primeira língua, e sim na segunda língua, isto é, o português (o surdo visualiza as mãos do TILS). E, se ele nunca viu aquela palavra, dificilmente irá dar um significado a ela.

Nos primeiros dias de aula, os alunos recusaram-se a ir à escola, em sinal de protesto. Entretanto, no decorrer do mês de março, os estudantes voltaram à escola e foram incluídos em salas regulares de ouvintes, com a presença do TILS. No mês de março de 2016, uma 
http://dx.doi.org/10.5902/1984686X42414

tutela antecipada, concedida pela justiça, garantiu a manutenção das classes especiais. Porém, a 6 ${ }^{\text {a }}$ CRE as multisseriou, ou seja, articulou as turmas de $6^{\circ}$ e $7^{\circ}$ ano em uma sala e as de $8^{\circ}$ e $9^{\circ}$ ano em outra, com alunos surdos e professores bilíngues. De certa forma, a comunidade surda considerou um pequeno avanço para a educação desses alunos, por não estarem mais incluídos em classes regulares. Mas, essa modalidade ainda não foi aceita pelos alunos e seus familiares, pois, nesse método de ensino, ainda havia consideráveis perdas.

Após mais de um mês de mobilização da comunidade surda, todos puderam comemorar a garantia do direito com o retorno das classes especiais, agora não mais multisseriadas. O dia 6 de abril de 2016 ficou representado como um marco histórico na ER, pois, nessa data, o Secretário da Seduc determinou que, a partir daquele próximo dia 11 de abril, as classes especiais voltariam a ser como eram antes das mudanças.

Conforme registros do jornal da cidade Riovale Jornal (2016), um dos comentários importantes a respeito dessa conquista partiu do representante da Federação Nacional de Educação e Integração dos Surdos (FENEIS), surdo, defensor e usuário da Libras, que sinalizou:

é direito de eles aprender em sua primeira língua a Língua Brasileira de Sinais (Libras). Estamos preocupados com o futuro dessas crianças que devem ter modelos para construir seu mundo. Tirar seu direito de aprender é tirar tudo que elas podem construir. (RIOVALE JORNAL, 2016, p. 7).

Ao término do encontro, o Secretário da Seduc, além da tão esperada determinação do retorno ao formato anterior das classes especiais na ER, também se justificou, conforme o registro do Riovale Jornal (2016), que:

A decisão destas mudanças tinha por objetivo a inclusão, porém, quando tomarmos conhecimento sobre cada detalhe, desde o momento em que recebemos a visão da comunidade surda, bem como a visita a escola, tivemos a plena certeza da necessidade dessas turmas, que seguirão normalmente. (RIOVALE JORNAL, 2016, p. 7).

Atualmente, a ER mantém suas atividades com as turmas do EF em classes especiais, assim como, no EM, com alunos surdos incluídos nas turmas regulares, com a presença de um TILS. Na verdade, esse profissional é um professor bilíngue da instituição que atua em outro turno em sala de aula, nas chamadas classes especiais. São 40 alunos que frequentam a instituição de ensino, os quais possuem diferentes idades e cidades, conforme a distribuição do quadro 1. 
http://dx.doi.org/10.5902/1984686X42414

Quadro 1 - Distribuição de alunos na instituição no ano de 2019:

\begin{tabular}{|c|c|c|}
\hline ANO ESCOLAR & TIPO DA TURMA & QUANTIDADE DE ALUNOS \\
\hline $2^{\circ}$ ano EF & Multisseriada & 2 \\
\hline $3^{\circ}$ ano EF & Multisseriada & 1 \\
\hline $4^{\circ}$ ano EF & Multisseriada & 3 \\
\hline $5^{\circ}$ ano EF & Única & 4 \\
\hline $6^{\circ}$ ano EF & Multisseriada & 1 \\
\hline $7^{\circ}$ ano EF & Multisseriada & 6 \\
\hline $8^{\circ}$ ano EF & Única & 7 \\
\hline $9^{\circ}$ ano EF & Única & 4 \\
\hline $1^{\circ}$ ano EM & Incluídos & 3 \\
\hline $2^{\circ}$ ano EM & Incluídos & 5 \\
\hline $3^{\circ}$ ano EM & Incluídos & \\
\hline & & \\
\hline
\end{tabular}

Fonte: dados da instituição, organizado pelos autores (2019).

\section{O processo de formação dos professores bilíngues na instituição de ensino referência na educação de surdos no Vale do Rio Pardo}

Nos primeiros anos da vinda dessa modalidade de ensino bilíngue para a escola, todos estavam adaptando-se, em especial os professores do EM, pela necessidade de entender sobre Libras e perceber essa cultura. Desse modo, fazer as primeiras leituras e observações para aprender como planejar as aulas para os alunos surdos.

Embora vários professores do EM tenham interesse pela educação de surdos, alguns desses são profissionais contratados. E, quando esses docentes estão experienciando práticas pedagógicas como desenvolver aulas que sejam interessantes e visuais, ou seja, que levem em consideração o mundo dos sujeitos surdos, são encaminhados para outra escola e chegam professores novos, recomeçando o ciclo.

Na referida escola, há também professores que, inicialmente, trabalhavam com alunos incluídos nas turmas regulares do EM, mas que, atualmente, estão ministrando aulas em Libras para os alunos do EF, nas turmas de classe especial.

Essa é a situação da primeira autora, que iniciou as atividades como docente na referida instituição, no início do ano de 2010, mesmo ano da chegada dos alunos surdos. Porém, a docente ministrava aulas de matemática nas turmas regulares e ainda não tinha experiência com a educação de surdos, ou seja, ter alunos surdos em sala de aula, mesmo com a presença do tradutor/intérprete de Libras, foi um grande desafio.

Observa-se que, em geral, essa disciplina não possibilita conhecimento para que se tenha uma comunicação com os sujeitos surdos. Nesse processo inicial, as dicas e trocas de experiências com as intérpretes, que são também professoras de surdos, foi essencial 
http://dx.doi.org/10.5902/1984686X42414

para que as primeiras relações de interesse ocorressem, com intuito de promover o ensinoaprendizagem nas aulas de matemática.

Nesse processo de formação que a primeira autora e outros professores passaram, houve a necessidade de que esses docentes tornassem-se bilíngues. Para isso, como também para ministrar aulas em Libras nas classes especiais, o primeiro critério é a graduação na área especifica. A seguir, carece fazer curso de especialização na área da surdez, para conhecer sobre a cultura, a história e a identidade surda. Também, foram necessárias várias horas de cursos de Libras em níveis básico, intermediário e avançado. Esses foram os primeiros encaminhamentos para aprofundar os conhecimentos sobre a educação de surdos.

\title{
Considerações finais
}

Após constituição da história da instituição que deu origem à presente pesquisa, a qual é referência na educação de surdos no Vale do Rio Pardo, percebeu-se os movimentos de resistência da comunidade surda e as lutas dessa minoria linguística para garantir seus direitos. A pesquisa foi fundamentada pelos estudos surdos e por outras pesquisas sobre a importância da língua de sinais, tais como a de Fronza e Muck (2012, p. 99), que salientam:

\begin{abstract}
A Libras precisa ter papel de destaque na educação de surdos, pois ela é fundamental na constituição da identidade desses sujeitos, permitindo-lhes reconhecerem se como parte integrante de uma comunidade e de uma cultura; além disso, é um elemento mediador entre os surdos e o meio social em que vivem, através do qual demonstram suas capacidades de interpretação do mundo. A língua portuguesa, na modalidade escrita, deve ser inserida no currículo bilíngue como segunda língua dos surdos, incluindo, assim, métodos de ensino focados na sua característica visual e na sua cultura. Nesse sentido, o ideal seria que a escola, mudando a sua concepção de língua como código e partindo de uma visão sociointeracionista, proporcionasse aos surdos o acesso à leitura e à escrita como prática social e cultural de linguagem, criando condições reais para sua inserção nestas práticas, a partir de suas especificidades. Além disso, seria importante que a escola redimensionasse 0 seu olhar sobre a escrita dos surdos, reconhecendo-a como uma escrita surda, que traduz a sua visão de mundo, o seu conhecimento de língua, o seu modo de ser, e, por isso, tem suas particularidades. (FRONZA, MUCK, 2012)
\end{abstract}

A respeito da aquisição da língua pelos surdos, Quadros (2006, p. 33) explica que:

Os alunos são dependentes das habilidades da sua primeira língua, particularmente, daquelas relacionadas ao letramento na primeira língua. $\mathrm{Na}$ perspectiva do desenvolvimento cognitivo, a aquisição de uma segunda língua é similar ao processo de aquisição da primeira língua. No entanto, deve ser considerada a inexistência de letramento na primeira língua. Os surdos não são letrados na sua língua quando se deparam com o português escrito. 
http://dx.doi.org/10.5902/1984686X42414

A escrita passa a ter uma representação na língua portuguesa ao ser mediada por uma língua que haja significação. As palavras não são ouvidas pelos surdos, eles não discutem sobre as coisas e seus significados no português, mas isso acontece na língua de sinais. Assim, a escrita do português é significada a partir da língua de sinais. (QUADROS, 2006)

Considerando esses autores e o contexto da educação de surdos da instituição, justifica-se os motivos para elencar e constituir esta trajetória que visa o respeito à diferença linguística do sujeito surdo. Esses indivíduos reconhecem como espaço legítimo de ensino a escola bilíngue de surdos. No que tange a essa questão, Thoma (2011, p. 139) argumenta:

para que as crianças surdas tenham uma efetiva aquisição da Libras e um desenvolvimento linguístico e cognitivo que Ihes possibilite uma escolarização de qualidade, a educação bilíngue para surdos em turmas específicas ou em escolas de surdos, na educação infantil e anos iniciais, segundo muitas pesquisas apontam, parece ser mais indicada. (THOMA, 2011).

Esse processo de militância e resistência da comunidade surda, por vezes, foi bem angustiante. Principalmente, quando se observava os alunos solicitando para não serem incluídos, uma vez que queriam aprender em LIBRAS. Todo esse movimento histórico, vivenciado e presenciado pela primeira autora, que resistiu, lutou e sentiu na pele todas essas angústias, culminou nas reflexões apresentadas no presente artigo. Essa trajetória serviu como aprendizagem, especialmente com relação à importância da união das minorias para a superação de barreiras.

Nos primeiros anos da vinda dessa modalidade de ensino bilíngue para a escola, todos estavam adaptando-se, em especial os professores do EM, pela necessidade de entender sobre LIBRAS e perceber essa cultura. Em outras palavras, fazer as primeiras leituras e observações para aprender como planejar as aulas para os alunos surdos. Para concluir, destaca-se a importância de publicizar experiências como a relatada no presente artigo, pois as dificuldades descritas podem ser enfrentadas, em qualquer momento, por outros grupos, visto as políticas públicas que estamos sujeitos.

\section{Referências}

BRASIL. Constituição. Lei no 13.146, de 06 de julho de 2015. Institui A Lei Brasileira de Inclusão da Pessoa Com Deficiência (Estatuto da Pessoa Com Deficiência). 2015.

BRASIL. Decreto n. 5626, de 22 de dezembro de 2005. 2005.

BRASIL. INES O que fazemos. 2012 - 2016. 2012. 
BRASIL. Instituto Nacional de Estudos e Pesquisas Educacionais Anísio Teixeira. Plano Nacional de Educação PNE 2014-2024: Linha de Base. - Brasília, DF: Inep, 2015.

BRASIL. MEC. PIBID - Apresentação. 2010. Disponível em: http://portal.mec.gov.br/pibid. Acesso em: 30 mai. 2019.

BRITO, Lucinda Ferreira. Integração social do surdo. In: Trabalhos em Lingüística Aplicada, no 7, p.13-22, 1986.

CAPOVILLA, Fernando César. Filosofias educacionais em relação ao surdo: do oralismo à comunicação total ao bilinguismo. Revista Brasileira de Educação Especial, v. 6, n. 1, 2000, p. 99-116.

CARVALHO, Naiana Santos. Surdez e Bilinguismo: perspectivas, possibilidades e práticas na educação para surdos - Salvador, 2010, p. 26.

CORREIA, Cláudio; FERNANDES, Eulália. Bilingüismo e Surdez: A evolução dos conceitos no domínio da linguagem; Capítulo I, In. FERNANDES, Eulália (organizadora). Surdez e Bilinguismo. Porto Alegre: Mediação, 2005.

FERANDEZ Eulália; RIOS, Katia Regina. Educação com bilingüismo para crianças surdas. Intercambio, v. VII, p. 13-21, 1998.

FREEMAN, Roger D.; CARBIN, Clifton F.; BOESE, Robert J. Seu filho não escuta? Um guia para todos que lidam com crianças surdas. Brasília: MEC/SEESP, 1999.

FRONZA, Cátia Azevedo; MUCK, Gisele Farias et al. Usando as chaves dos conceitos sobre concepções quanto ao ensino e à aprendizagem de língua por surdos. In: LOPES, Maura Corcini et al. Cultura Surda \& Libras. Porto Alegre: Editora Unisinos, 2012. Cap. 5. p. 78-107.

GOÉS, Maria Cécilia Rafael. Linguagem, surdez e educação. Campinas: Autores Associados, 1996.

GUEDES, Betina S. et al. Educação de surdos: percursos históricos. In: LOPES, Maura Corcini et al. Cultura Surda \& Libras. Porto Alegre: Editora Unisinos, 2012. Cap. 1. p. 10-27.

KIPPER, Daiane. Práticas matemáticas visuais produzidas por alunos surdos: entre números, letras e sinais. Santa Cruz do Sul: UNISC, 2015. p. 156.

PEREIRA, Rachel de Carvalho. Surdez: aquisição de linguagem e inclusão social. Rio de Janeiro: Revinter, 2008.

PETIÇÃO Publica: Apoio à Escola Rosário de Santa Cruz do Sul/RS. 2015. Disponível em: https://peticaopublica.com.br/pview.aspx?pi=BR88415. Acesso em: 15 abr. 2019.

QUADROS, Ronice Müller de. Idéias para ensinar português para alunos surdos / Ronice Muller Quadros, Magali L. P. Schmiedt. - Brasília: MEC, SEESP, 2006. 
http://dx.doi.org/10.5902/1984686X42414

REGIMENTO ESCOLAR. (Estado). Constituição (2017). Regimento Escolar nํ 30.644, de 2017. Regimento Escolar: Escola Estadual de Ensino Médio Nossa Senhora do Rosário. Santa Cruz do Sul, RS.

RIOVALE JORNAL: 6므 CRE extingue turmas para surdos. Santa Cruz do Sul, 20 fev. 2016. Disponível em: http://www.riovalejornal.com.br/edicao/731-20.02.2016. Acesso em: 21 abr. 2019.

RIOVALE JORNAL: Vieira da Cunha garante as classes especiais para surdos. Santa Cruz do Sul, 09 abr. 2016. Disponível em: http://www.riovalejornal.com.br/edicao/74809.04.2016. Acesso em: 21 abr. 2019.

THOMA, Adriana da Silva. Educação Bilíngue para surdos no contexto da educação inclusiva. In: MORAES, Salete Campos de (org.). Educação inclusiva: diferentes significados. Porto Alegre - RS: Editora Evangraf, 2011.

ZANDONATO, Lisnara Pra; KLEIN, Denise; BERTÓ, Suzana Fardin. Inclusão ao inverso. 32 Enel (Encontro Nacional dos Estudantes de Letras) e 1은 $\mathrm{SNL}$ (Seminário Nacional de Libras), Goiás, v. 1, n. 1, p.128-128, 2011.

ZILIO, Virgínia Maria. A Língua Surda. In: LOPES, Maura Corcini et al. Cultura Surda \& Libras. Porto Alegre: Editora Unisinos, 2012. Cap. 2. p. 28 - 40.

\section{Notas}

10 método oralista objetivava levar o surdo a falar e a desenvolver competência linguística oral, o que the permitiria desenvolver-se emocional, social e cognitivamente do modo mais normal possível, integrando-se, como um membro produtivo ao mundo dos ouvintes (CAPOVILLA, 2000, p. 102).

2 Helen Adams Keller foi uma mulher que, apesar de cega e surda desde a infância, superou todos os obstáculos, tornando-se uma escritora e jornalista (CARVALHO, 2010, p. 26).

${ }^{3} \mathrm{Na}$ década de 1970, com a visita de Ivete Vasconcelos, educadora de surdos da Universidade Gallaudet, chegou ao Brasil a filosofia da Comunicação Total (PEREIRA,2008).

${ }^{4} \mathrm{O}$ transporte é facilitado devido à UNISC receber alunos universitários de vários municípios e nos turnos (manhã, tarde e noite), podendo assim, também transportar os alunos até a ER, que está localizada a aproximadamente 600 metros da universidade.

${ }^{5} \mathrm{Na}$ escola foco da pesquisa, os alunos surdos estudam em classes nomeadas "especiais para surdos". Quando não há escolas de surdos no município-polo ou em municípios vizinhos, a comunidade surda recomenda que esses estudantes sejam atendidos em classes especiais, nas quais devem ser tratados como pessoas com cultura surda, língua e comunidade diferente (FENEIS, 1999. apud. KIPPER, 2015, p.21). O conceito "especial" está em desuso, porém faz parte da documentação da escola, fator esse que contribuiu para sua manutenção neste artigo.

${ }^{6} \mathrm{O}$ programa oferece bolsas de iniciação à docência aos alunos de cursos presenciais que se dediquem ao estágio nas escolas públicas e que, quando graduados, se comprometam com o exercício do magistério na rede pública. O objetivo é antecipar o vínculo entre os futuros mestres e as salas de aula da rede pública. Com essa iniciativa, o Pibid faz uma articulação entre a educação superior (por meio das licenciaturas), a escola e os sistemas estaduais e municipais. (BRASIL, 2010). 
http://dx.doi.org/10.5902/1984686X42414

\section{Correspondência}

Neoli Paulina da Silva Gabe - Av. Roraima, no 1000, Cidade Universitária Bairro, Camobi, Santa Maria, Rio Grande do Sul - Brasil.

CEP: $97105-900$

\section{(c) (7) (8)}

4.0 International (CC BY-NC 4.0) 